\title{
Postural studies in pulsatile ocular blood flow: II. Chronic open angle glaucoma
}

Division of

Pharmacological

Sciences and Toxicology,

United Medical and

Dental Schools,

St Thomas's Campus,

London SE1 7EH

D R Trew

$S$ E Smith

Correspondence to:

Mr D R Trew, Department

of Clinical Pharmacology,

St Thomas's Hospital,

London SE1 7EH.

Accepted for publication

16 August 1990

\author{
D R Trew, S E Smith
}

\begin{abstract}
The pulsatile ocular blood flow (POBF) has been recorded in 15 patients with chronic open angle glaucoma. Measurements were performed during regular treatment with timolol $0 \cdot 25 \%$ eyedrops, two weeks after withdrawal of this treatment, and then a further two weeks after its reinstitution. Readings were taken with subjects in both the erect and supine positions by means of a pneumotonometric probe to measure intraocular pressure (IOP), linked to a Langham ocular blood flow system. Assumption of the supine posture was associated with a significant increase in IOP in all phases of the study. Treatment with timolol lowered the mean IOP in comparison with the untreated phase $(-4.4$ (SEM 0.6) $\mathrm{mmHg}$, $p<0.001$ ) but had no effect on the postural change. A significant reduction in POBF was recorded on assumption of the supine posture (-66 (SEM 18) $\mu \mathrm{l} / \mathrm{min}, p<0.001$ ), representing a mean decrement of $19 \%$. However, there were no significant differences in POBF between treated and untreated phases of the study. Comparison of the values obtained in patients with glaucoma (COAG) after withdrawal of treatment with those in subjects with ocular hypertension revealed that there was no significant difference in intraocular pressure between the two groups. However, both POBF (-68 (SEM 29) $\mu \mathrm{l} / \mathrm{min}$ ) and the pulse amplitude of the intraocular pressure (ocular pulse: -0.45 (SEM) $0.14 \mathrm{mmHg}$ ) were significantly lower in the COAG patients. Pulsatile ocular blood flow is significantly lower in patients with chronic open angle glaucoma. Furthermore, the POBF and the postural response of these patients is not improved by the use of topical timolol therapy.
\end{abstract}

Standard treatments for chronic open angle glaucoma rely exclusively on the reduction of intraocular pressure (IOP). Despite apparent satisfactory pressure control, visual function declines progressively in a proportion of patients. ${ }^{1-5}$ One possible explanation is that ocular blood flow is impaired in these patients, particularly when they are recumbent. We have described a significant reduction in pulsatile ocular blood flow (POBF) in ocular hypertensives and normotensives on assuming the supine posture from the upright. ${ }^{6}$ Intraocular pressure rises in the supine position, ${ }^{78}$ and this may lower perfusion pressure, which would eventually reduce blood flow. ${ }^{9}$ Furthermore, this postural response of the IOP is greater in ocular hypertensive ${ }^{10}$ and glaucoma subjects ${ }^{11}$ and the effect is known to persist despite hypotensive treatment. ${ }^{1213}$
Photographic studies have shown that treatment with topical timolol reduces retinal arterial calibre. ${ }^{14}$ There is some evidence also, in rabbits, of a resultant reduction in blood flow, ${ }^{15}$ though the opposite has also been demonstrated in humans. ${ }^{16}$ These effects are thought to be mediated by a direct effect on vascular $\beta-2$ receptors ${ }^{17}$ irrespective of the hypotensive effect of timolol. These studies illustrate effects on retinal circulation, but this represents only a small percentage of total ocular blood flow, most of which passes through the ciliochoroidal system..$^{119}$ They therefore take no account of the major blood supply via the posterior ciliary circulation, particularly to the optic nerve head. Although some workers consider vessels in this region to demonstrate autoregulation, ${ }^{20-22}$ like that of the retinal vessels, ${ }^{92324}$ it is difficult to substantiate, particularly as the rest of the choroidal system appears not to be autoregulated..$^{25}$ Interestingly, there has been some evidence from reflectometry and photography that intraocular pressure rises affect blood flow through the choroid in the peripapillary region significantly more than in the retinal circulation. ${ }^{26}$

The pulsatile component of total ocular flow may be derived from measurements of intraocular pressure ${ }^{27}$ by applanation pneumotonometry linked to a Langham ocular blood flow system. ${ }^{28}$ In this study we have investigated the relationship of pulsatile ocular blood flow (POBF) to posture in patients with chronic open angle glaucoma receiving treatment with topical timolol $\mathbf{0} \cdot \mathbf{2 5 \%}$. Comparison has been made with a group of healthy ocular hypertensive subjects described in our companion paper. ${ }^{6}$

\section{Subjects and methods}

\section{SUBJECTS}

Fifteen patients, six male and nine female, with chronic open angle glaucoma (COAG) were recruited from the outpatients department. The mean age of the group was $67 \cdot 4$ years (range 42 78). Each was under treatment solely with topical timolol $0 \cdot 25 \%$ twice daily and was receiving no systemic medication. There were no diabetics or systemic hypertensives in the group. Each gave written consent to participate, and the study was approved by the Ethics Committee of West Lambeth Health Authority.

\section{STUDY DESIGN}

The patients were studied on three occasions: (1) while receiving regular treatment with timolol $0 \cdot 25 \%$ eyedrops; (2) two weeks after withdrawal of the treatment; and (3) a further 
two weeks after its reinstitution. The patients attended at the same time of day on each occasion.

\section{METHODS}

Measurements of intraocular pressure and ocular pulse amplitude were obtained by applanation pneumotonometry linked to a Langham ocular blood flow system, performed after instillation of $0.4 \%$ benoxinate. Simultaneous recordings were made of heart rate by standard electrocardiogram (ECG) and mean systemic blood pressure (diastolic plus one-third of the pulse pressure) with a Takeda Medical UA-751 Digital blood pressure meter. Measurements were performed in duplicate with the subject standing and, after 15 minutes' rest, supine.

Values of POBF were derived from the intraocular pressure pulse waveform and amplitude together with the heart rate, as described in the companion paper. ${ }^{6}$

\section{STATISTICAL ANALYSIS}

Postural and treatment effects on POBF, intraocular pressure, ocular pulse amplitude, heart rate, and mean blood pressure were compared by analysis of variance appropriate for an experiment of factorial design. ${ }^{29}$ In the analysis of the following results no significant interaction was found for any of the recorded or calculated variables between patient groups and the postural changes observed. Similarly for the COAG patients no significant interactions were found between treatment (timolol) effects and the postural changes which occurred. In these comparisons, therefore, it is assumed that the postural effects are independent of patient groups and treatment, and they are reported as such. Comparisons of the same variables, between COAG patients off treatment and ocular hypertensives studied in our companion paper, ${ }^{6}$ were made in the same way.

Comparisons between the on-treatment phase and the retreatment phase in COAG patients for the above variables were made by Student's paired $t$ test.

\section{Results}

There were no significant differences between values for the right and left eyes, so for clarity of presentation the tables and figures illustrate effects on the right eye only. There were no significant differences between patients receiv-

Table 1 Differences between treated and retreated phases, in COAG patients, in ocular and systemic variables concerned in pulsatile ocular blood flow: mean (SEM)

\begin{tabular}{|c|c|c|c|c|c|}
\hline Variable & Posture & Treated & Retreated & Mean difference & $p$ \\
\hline Heart rate $(\mathrm{bpm})$ & $\begin{array}{l}\text { Erect } \\
\text { Supine }\end{array}$ & $\begin{array}{l}73 \cdot 8(3 \cdot 5) \\
64 \cdot 8(2 \cdot 9)\end{array}$ & $\begin{array}{l}72 \cdot 9(2 \cdot 5) \\
66.9(2 \cdot 1)\end{array}$ & $\begin{array}{l}0.9 \\
2 \cdot 1\end{array}$ & $\begin{array}{l}\text { NS } \\
\text { NS }\end{array}$ \\
\hline Mean $\mathrm{BP}(\mathrm{mmHg})$ & Erect & $104 \cdot 8(3 \cdot 7)$ & $103 \cdot 6(4 \cdot 3)$ & $1 \cdot 2$ & NS \\
\hline & Supine & $97 \cdot 1(3 \cdot 5)$ & $95 \cdot 1(3 \cdot 3)$ & $2 \cdot 0$ & NS \\
\hline IOP (mmHg) & Erect & $18 \cdot 8(0.9)$ & $17 \cdot 8(0.9)$ & 1.0 & NS \\
\hline & Supine & $22.9(1.0)$ & $21.7(0.9)$ & $1 \cdot 2$ & NS \\
\hline Pulse amplitude & Erect & $1 \cdot 7(0 \cdot 1)$ & $1 \cdot 7(0 \cdot 1)$ & 0 & NS \\
\hline$(\mathrm{mmHg})$ & Supine & $1 \cdot 7(0 \cdot 1)$ & $1 \cdot 7(0 \cdot 1)$ & 0 & NS \\
\hline POBF $(\mu \mathrm{l} / \mathrm{min})$ & Erect & $365(29)$ & $389(32)$ & 24 & NS \\
\hline
\end{tabular}

NS $=$ not significant

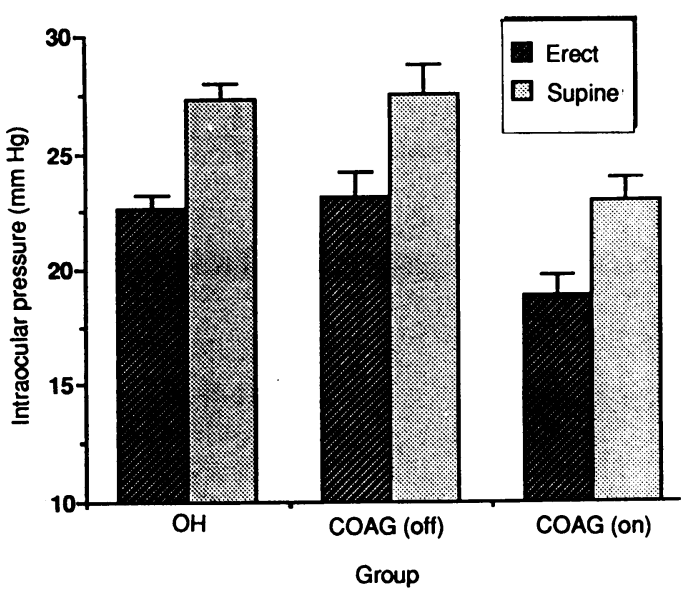

Figure 1 Effect of posture on mean intraocular pressure in the right eye. Groups shown: ocular hypertensives $(\mathrm{OH})$, untreated (off) and treated (on) glaucoma patients. Vertical lines indicate SEM.

ing treatment with timolol eyedrops and having reinstituted treatment in the third phase of the study (Table 1). Comparisons are made therefore between treated and untreated phases.

Group mean values for IOP, ocular pulse amplitude, and POBF of ocular hypertensive subjects (from the companion study ${ }^{6}$ ) and of glaucoma patients off and on timolol treatment in erect and supine positions are shown in Figures 1, 2, and 3 respectively. The relationship between IOP and POBF in the glaucoma patients is illustrated in Figure 4.

\section{COMPARISON BETWEEN COAG AND OCULAR} HYPERTENSIVE PATIENTS

Group differences and postural effects are given in Table 2. By comparison with ocular hypertensives, COAG patients had a significantly reduced ocular pulse amplitude $(p<0.01)$ and POBF $(p<0.05)$ without difference in heart rate, mean blood pressure, or IOP. Assumption of the supine position was associated with a significant fall in heart rate $(p<0.001)$, a rise in IOP $(p<0.001)$, and a reduction in POBF $(p<0.05)$ without change in mean blood pressure or ocular pulse amplitude. The lack of statistical interaction (see above) indicates that the postural changes did not differ between the patient groups.

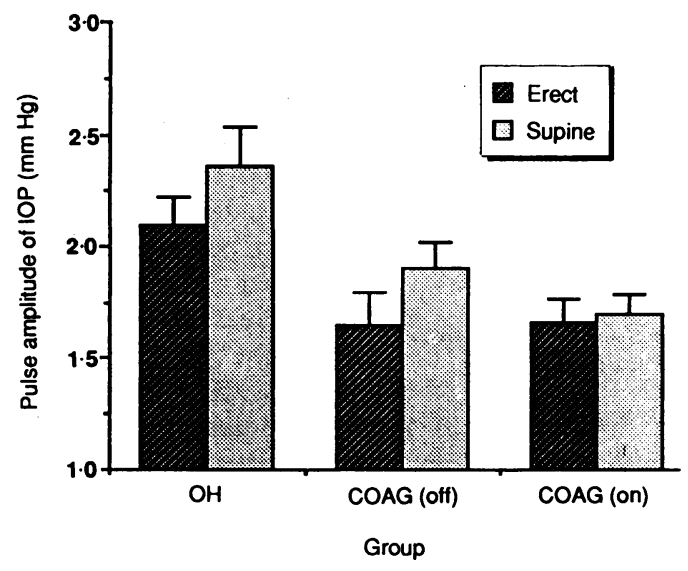

Figure 2 Effect of posture on the mean pulse amplitude of intraocular pressure in the right eye. Symbols as for Figure 1. 


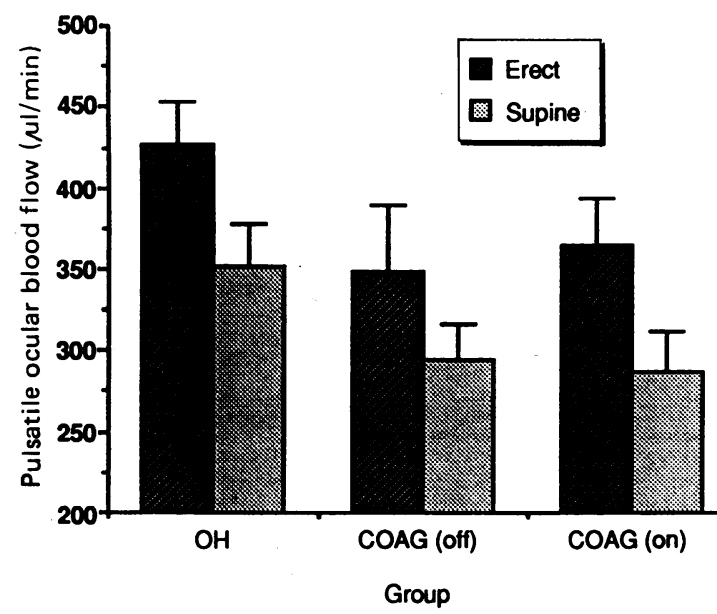

Figure 3 Effect of posture on the mean pulsatile ocular blood flow in the right eye. Symbols as for Figure 1.

EFFECTS OF TIMOLOL TREATMENT

Treatment and postural effects in COAG patients are given in Table 3 . Timolol significantly reduced heart rate $(p<0.001)$ and IOP $(p<0.001)$ but did not alter mean blood pressure, ocular pulse amplitude, or POBF. In these subjects assumption of the supine position significantly reduced heart rate $(\mathrm{p}<0.001)$ and mean blood pressure $(p<0.01)$, caused a rise in IOP $(\mathrm{p}<0.01)$ and a reduction in POBF $(p<0.001)$, but was without effect on ocular pulse amplitude. The lack of statistical interaction (see above) indicates that timolol treatment did not alter the ocular or systemic responses to postural change.

\section{RESPONSES OF INDIVIDUAL PATIENTS}

Figure 5 shows the responses of intraocular pressure to drug treatment. It demonstrates that in many patients IOP was lowered close to, if not within, the normal range. Individual patient results for changes in pulsatile ocular blood flow are illustrated in Figure 6 and provide a contrast to the IOP findings. In the supine posture, when $P O B F$ values are at a minimum, timolol

Table 2 Comparison between untreated $C O A G$ patients and ocular hypertensive $(O H)$ subjects and postural effects on ocular and systemic variables concerned with pulsatile ocular blood flow

\begin{tabular}{|c|c|c|c|c|c|c|c|c|}
\hline \multirow[b]{2}{*}{ Variable } & \multicolumn{4}{|c|}{ Group comparison (COAG-OH) } & \multicolumn{4}{|c|}{ Postural effect (lying-standing) } \\
\hline & Mean & $S E M$ & $t$ & $p$ & Mean & $S E M$ & $t$ & $p$ \\
\hline $\begin{array}{l}\text { Heart rate }(\mathrm{bpm}) \\
\text { Mean } \mathrm{BP}(\mathrm{mmHg}) \\
\text { IOP }(\mathrm{mmHg}) \\
\text { Pulse amplitude }(\mathrm{mmHg}) \\
\text { POBF }(\mu \mathrm{l} / \mathrm{min})\end{array}$ & $\begin{array}{c}1 \cdot 8 \\
0 \cdot 2 \\
0 \cdot 3 \\
-0 \cdot 45 \\
-68\end{array}$ & $\begin{array}{l}3 \cdot 6 \\
3 \cdot 0 \\
0 \cdot 9 \\
0 \cdot 14 \\
29\end{array}$ & $\begin{array}{r}0.516 \\
0.070 \\
0.344 \\
-3 \cdot 197 \\
-2-296\end{array}$ & $\begin{array}{l}\text { NS } \\
\text { NS } \\
\text { NS } \\
<0.01 \\
<0.05\end{array}$ & $\begin{array}{c}-14 \cdot 7 \\
-5 \cdot 4 \\
4 \cdot 6 \\
0 \cdot 26 \\
-65\end{array}$ & $\begin{array}{l}3.6 \\
3 \cdot 0 \\
0.9 \\
0 \cdot 14 \\
29\end{array}$ & $\begin{array}{r}-4 \cdot 041 \\
-1 \cdot 089 \\
5 \cdot 091 \\
1 \cdot 802 \\
-2 \cdot 226\end{array}$ & $\begin{array}{l}<0.001 \\
\text { NS } \\
<0.001 \\
\text { NS } \\
<0.05\end{array}$ \\
\hline
\end{tabular}

NS=not significant.

Table 3 Differences between treated (a) and untreated (b) COAG patients and postural effects on ocular and systemic variables concermed with pulsatile ocular blood flow

\begin{tabular}{|c|c|c|c|c|c|c|c|c|}
\hline \multirow[b]{2}{*}{ Variable } & \multicolumn{4}{|c|}{ Treatment effect $(a-b)$} & \multicolumn{4}{|c|}{ Postural effect (lying-standing) } \\
\hline & Mean & $S E M$ & $t$ & $p$ & Mean & $S E M$ & $t$ & $p$ \\
\hline $\begin{array}{l}\text { Heart rate }(\mathrm{bpm}) \\
\text { Mean BP }(\mathrm{mmHg}) \\
\text { IOP }(\mathrm{mmHg}) \\
\text { Pulse amplitude }(\mathrm{mmHg}) \\
\text { POBF }(\mu \mathrm{l} / \mathrm{min})\end{array}$ & $\begin{array}{l}-6 \cdot 7 \\
-0.9 \\
-4 \cdot 4 \\
-0.09 \\
5\end{array}$ & $\begin{array}{c}1.6 \\
1.7 \\
0.6 \\
0.08 \\
18\end{array}$ & $\begin{array}{r}-4.042 \\
-0.506 \\
-7.234 \\
-1.134 \\
0.253\end{array}$ & $\begin{array}{l}<0.001 \\
\text { NS } \\
<0.001 \\
\text { NS } \\
\text { NS }\end{array}$ & $\begin{array}{c}-11 \cdot 5 \\
-5 \cdot 7 \\
4 \cdot 2 \\
0 \cdot 15 \\
-66\end{array}$ & $\begin{array}{c}1 \cdot 6 \\
1 \cdot 7 \\
0 \cdot 6 \\
0 \cdot 08 \\
18\end{array}$ & $\begin{array}{r}-6.994 \\
-3.388 \\
6.907 \\
1.793 \\
-3.588\end{array}$ & $\begin{array}{l}<0.001 \\
<0.01 \\
<0.01 \\
\text { NS } \\
<0.001\end{array}$ \\
\hline
\end{tabular}

NS= not significant.

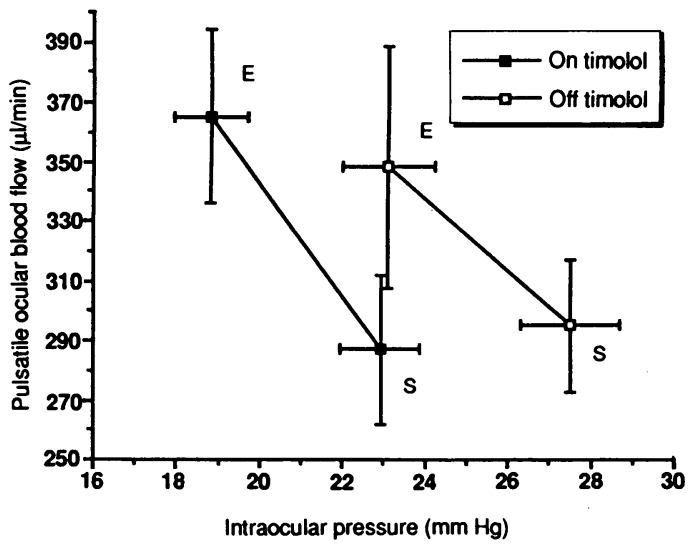

Figure 4 Effect of intraocular pressure on mean pulsatile ocular blood flow in the right eye of glaucoma patients when on and off timolol treatment. Vertical and horizontal lines indicate $S E M$. $E=$ erect. $S=$ supine.

markedly reduced flow still further in two of the 15 patients. In one of these the flow was reduced by $44 \%$ and in the other by $40 \%$. In addition three further patients in this group had persistently low values of POBF which failed to change in response to drug treatment.

\section{Discussion}

Two important matters emerge from these observations. First, pulsatile ocular blood flow is significantly lower in patients with chronic open angle glaucoma than in subjects with ocular hypertension. Secondly pulsatile ocular blood flow and the postural response of these patients are not improved by the use of topical timolol therapy despite the resulting fall in IOP.

The general pattern of observations made on the glaucoma patients is similar to that made in healthy ocular normotensive and hypertensive subjects and illustrated in our companion paper. ${ }^{6}$ Assumption of the supine posture was associated with a rise in IOP in all phases of the study. Timolol treatment lowers the IOP in both postures, but it does not alter the postural change, as stated above. Similar observations have been made previously in ocular normotensives and glaucoma patients after instillation of topical $\beta$ blockers. ${ }^{12}{ }^{13}$ Our patients received Ethics Committee approval for treatment withdrawal for a period of two weeks prior to measurement in the 'untreated' phase of the study. We recognise that this study design was not ideal, as some residual treatment effects may persist after this period of time. ${ }^{30}$ Despite this, however, our results have demonstrated significant changes following treatment withdrawal, and any remaining effects would be small and unlikely to affect the validity of the overall results.

At the same time our COAG patients had a decreased POBF on lying down, as did subjects with ocular hypertension. The values for mean blood pressure followed a similar pattern. However, timolol treatment did not change POBF in either posture nor did it alter the postural change. In the glaucoma patients this would indicate that taken as a group, institution of timolol treatment, while reducing IOP, does not improve ocular perfusion. Similar findings have been suggested in other studies on vascular 

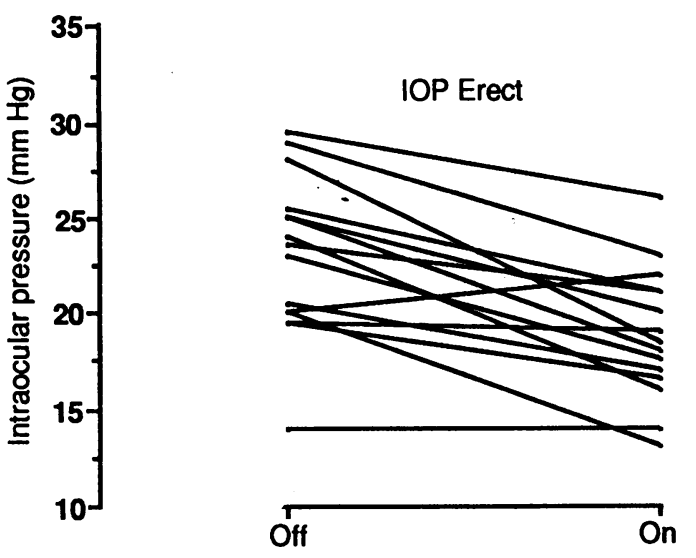

Treatment phase
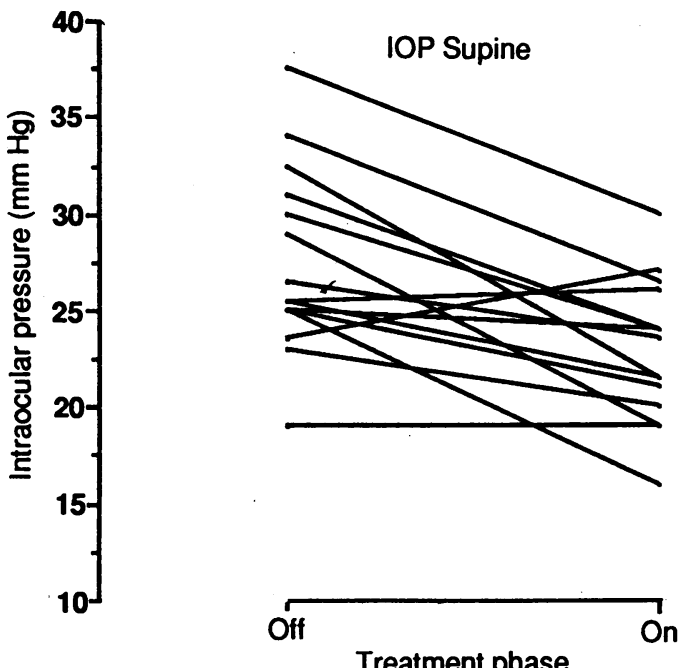

Figure 5 Changes in intraocular pressure for the right eye of individual glaucoma subjects when off and on timolol treatment. Above: erect. Below: supine.

parameters in timolol treated subjects. ${ }^{31} 32$ This observation is interesting because it suggests that the general vascular responses to this drug, such as a decreased heart rate and a reduction in blood pressure, may counteract the benefits accruing from its ocular hypotensive action.

Inspection of the data from individual patients showed that timolol adversely affected POBF in two of 15 patients in the supine posture. This reduction in blood flow may have important consequences not only for the perfusion of the optic nerve head but also for the outer layers of the retina, which are supplied via the choroidal circulation and which have such high metabolic requirements.

These observations have shown that the POBF and the postural response of glaucoma subjects were not improved by the use of topical timolol therapy. In some cases the values worsened in the supine position in comparison with the untreated phase. This may provide a basis for understanding the mechanisms underlying treatment failure in this type of patient, such as peripheral vasoconstriction locally, or reduction in heart rate systemically. Further prospective studies are required to confirm this finding and to relate it to long term changes in visual field defects. These observations suggest that research is needed into treatments which may by one mechanism or another improve blood flow to the diseased eye.
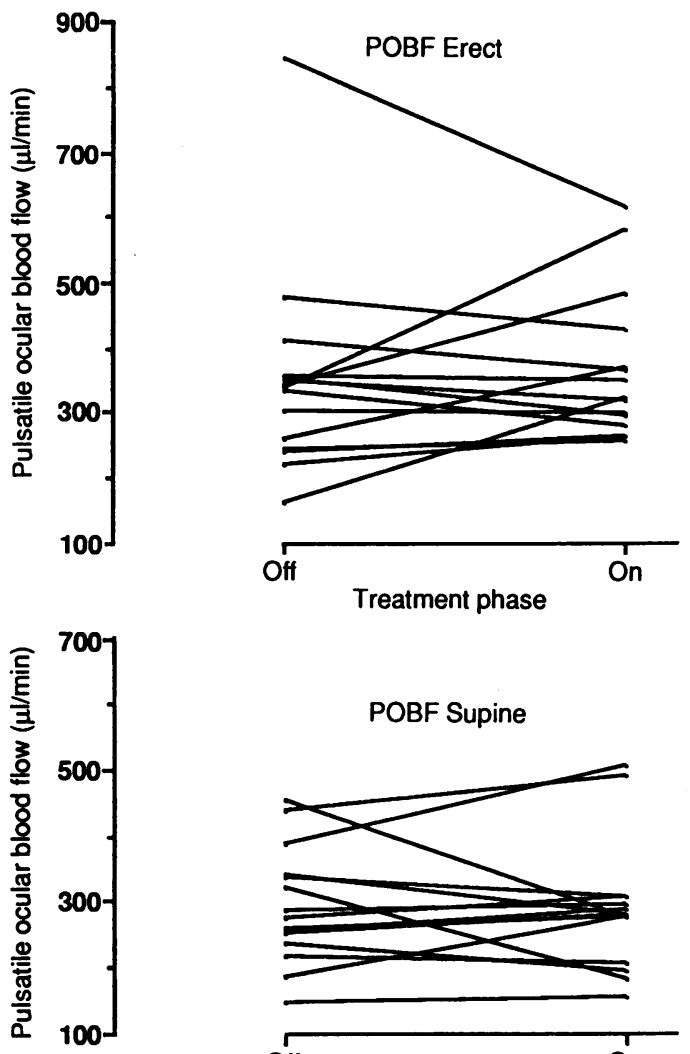

POBF Supine

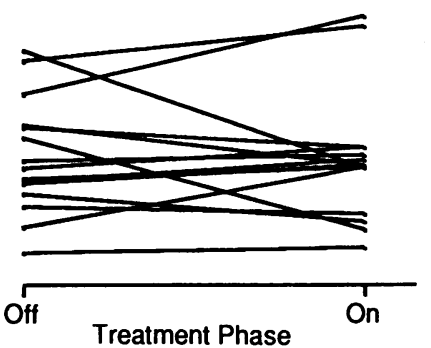

Figure 6 Changes in pulsatile ocular blood flow for the right eye of individual glaucoma subjects when off and on timolol treatment. Above: erect. Below: supine.

We thank Mr M Falcon and Mr D Spalton for allowing us to study their patients, Karen Clark and Raymond Allen for technical help, their patients, Karen Clark and Raymond Allen for technical help, nd Jan Andrews for secretarial assistance.

DRT is supported by the Iris Fund for Prevention of Blindness and the Special Trustees of St Thomas's Hospital. Financial support for the study was kindly provided by the Royal National Institute for the Blind.

1 Schulzer M, Mikelberg FS, Drance SM. Some observations on the relation between intraocular pressure reduction and the progression of glaucomatous visual loss. $\mathrm{Br} \mathcal{F}$ Ophthalmol 1987; 71: 486-8.

2 Flammer J, Drance SM. The effect of glaucoma medications on the differential light threshold. Doc Ophthalmol Proc Ser 1983; 35: 146-8.

3 Flammer J, Drance SM. Influence of pindolol and timolol treatment on the visual fields of glaucoma patients. $\mathcal{F}$ Ocul Pharmacol 1986; 2: 305-11.

4 Smith RJH. The Lang Lecture 1986. The enigma of primary open-angle glaucoma. Trans Ophthalmol Soc UK 1986; 105: open-angle

5 Kidd MN, O'Connor M. Progression of field loss after trabeculectomy: a five-year follow-up. Br $\mathcal{F}$ Ophthalmol 1985; 69: 827-31.

6 Trew DR, Smith SE. Postural studies in pulsatile ocular blood flow: I. Ocular hypertension and normotension. $\mathrm{Br} \mathcal{F}$ Ophthalmol 1991; 75: 66-70.

7 Galin MA, McIvor JW, Magruder GB. Influence of position on intraocular pressure. Am f Ophthalmol 1963; 55: 720-3.

8 Anderson DR, Grant WM. The influence of position on IOP. Invest Ophthalmol Vis Sci 1973; 12: 204-12.

9 Ffytche TJ, Bulpitt CJ, Kohner EM, Archer D, Dollery CT. Effect of changes in intraocular pressure on the retinal Effect of changes in intraocular pressure on the
microcirculation. Br 7 Ophthalmol 1974; 58: $514-22$.

10 Leonard TJK, Kerr Muir MG, Kirkby GR, Hitchings RA Ocular hypertension and posture. Brf Ophthalmol 1983; 67: Ocular hyp

11 Tsukahara S, Sasaki T. Postural change of IOP in normal persons and in patients with primary wide open-angle glaucoma and low-tension glaucoma. Br f Ophthalmol 1984; 68: 389-92.

12 Smith DA, Trope GE. Effect of beta-blockers on altered body position induced ocular hypertension. Invest Ophthalmol Vis $S c i$ 1989; 26. ARVO.

13 Parsley J, Powel RG, Keightley SJ, Elkington AR. Postural response of intraocular pressure in chronic open-angle glaucoma following trabeculectomy. Br 7 Ophthalmol 1987; 71: 494-6.

14 Martin XD, Rabineau PA. Vasoconstrictive effect of topical timolol on human retinal arteries. Graefes Arch Clin Exp Ophthalmol 1989; 227: 526-30.

15 Yan H-Y, Chiou GCY. Effects of L-timolol, D-timolol, haloperidol and domperidone on rabbit retinal blood flow 
measured with laser Doppler method. Ophthalmic Res 1987; 19: 45-8.

16 Grunwald JE. Effect of topical timolol on the human retinal circulation. Invest Ophthalmol Vis Sci 1986; 27: 1713-9.

17 Ferrari-Dileo G. Beta ${ }_{1}$ and beta ${ }_{2}$ adrenergic binding sites in bovine retina and retinal blood vessels. Invest Ophthalmol Vis Sci 1988; 29: 695-701.

18 Langham ME. Ocular blood flow and visual loss in glaucomatous eyes. In: Krieglstein GK, ed. Glaucoma update III. Berlin, Heidleberg: Springer, 1987: 58-66.

19 Roy MS, Harrison KS, Harvey E, Mitchell T. Ocular blood flow in dogs using radiolabelled microspheres. Int J Radiat Appl Instrum (B) 1989; 16: 81-4.

20 Anderson DR. The posterior segment of glaucomatous eyes. Basic aspects of glaucoma research. Stuttgart: Schattauer,

21 Sossin, Anderso.

on blood flow. Occurrence in cat optic nerve head studied with iodoantipyrine I-125. Arch Ophthalmol 1983; 101: 98101 .

$22 \mathrm{Alm}$ A. Microspheres in optic nerve blood flow measurements. In: Lambrou GN, Greve EL, eds. Ocular blood flow in glaucoma. Amsterdam: Kugler and Ghedini, 1989: 65-8.

23 Riva CE, Grunwald JE, Petrig BL. Autoregulation of human retinal blood flow. An investigation with laser Doppler velocimetry. Invest Ophthalmol Vis Sci 1986; 27: velocimetry.
24 Stefansson E, Wagner HG, Seida M. Retinal blood flow and its autoregulation measured by intraocular hydrogen clearance. Exp Eye Res 1988; 47: 669-78.

25 Bill A, Sperber GO. Control of retinal and choroidal blood low. Eye 1990; 4: 319-25.

26 Nagasubramian S, Perkins ES, Gloster J. Combined reflectometric and photographic study of the retinal and choroidal circulation at raised intraocular pressure. Trans Ophthalmol Soc UK 1977; 97: 177-84.

27 Silver DM, Farrell RA, Langham ME, O'Brien V, Schilder P. Estimation of pulsatile ocular blood flow from introacular pstimation of pulsatile ocular blood flow from introacular

28 Langham ME, Farrell RA, O'Brien V, Silver DM, Schilder P. Blood flow in the human eye. Acta Ophthalmol (Kbh) 1989; 67 (suppl 191): 9-12.

29 Snedecor GW, Cochran WG. Analysis of factorial experiments. Statistical methods. 6th ed. Iowa State University Press: Ames, 1967.

30 Schlecht LP, Brubaker RF. The effects of withdrawal of timolol in chronically treated glaucoma patients. Ophthalmology 1988; 95: 1212-6.

31 Pillunat L, Stodtmeister R. Effect of different antiglaucomatous drugs on ocular perfusion pressures. $\mathcal{F}$ Ocul Pharmacol 1988; 4: 231-42.

32 Grunwald JE, Furubayashi C. Effect of topical timolol maleate on the ophthalmic artery blood pressure. Invest Ophthalmol Vis Sci 1989; 30: 1095-100. 